\title{
Suicide notes from Mexico and the United States: a thematic analysis
}

\author{
Ana-María Chávez-Hernández, PhD, (1) Antoon A Leenaars, PhD, (2) \\ María-Isabel Chávez-de Sánchez, PhD, ${ }^{(2)}$ Lindsey Leenaars, MEd ${ }^{(3)}$
}

\author{
Chávez-Hernández AM, Leenaars AA, \\ Chávez-de Sánchez MI, Leenaars L. \\ Suicide notes from Mexico and the United States: \\ a thematic analysis. \\ Salud Publica Mex 2009;5 I:3 | 4-320.
}

\begin{abstract}
Objective. This study sought to investigate suicide notes drawn from Mexico and the United States (US) as these countries share geographical proximity, but markedly different cultures and suicide rates. Material and Methods. A theoretical conceptual analysis of 102 suicide notes drawn from these countries, matched for age and sex, was undertaken based on a thematic model of suicide developed by Leenaars, ${ }^{1,2}$ across countries. Results. The inter-judge reliability was adequate (.86 coefficient of concordance). Conclusions. The results suggested that there are more psychological commonalities than differences. Yet, as this study marks the first one using suicide notes, between Mexico and the USA, much greater study is warranted.
\end{abstract}

Key words: suicide/psychology; thematic analysis; comparative study, Mexico, United States
Chávez-Hernández AM, Leenaars AA

Chávez-de Sánchez MI, Leenaars L.

Notas suicidas de México y Estados Unidos:

un análisis temático.

Salud Publica Mex 2009;5 I:3 | 4-320.

\section{Resumen}

Objetivo. Este estudio tuvo por objetivo la comparación de notas suicidas (póstumas) de México y de Estados Unidos, países que aunque vecinos geográficos, presentan marcadas diferencias culturales y porcentajes de suicidio. Material y métodos. Se realizó un análisis conceptual de 102 notas (5I mexicanas, $5 \mathrm{I}$ estadunidenses), pareadas por edad y sexo. Se utilizó el Modelo temático de suicidio desarrollado por Leenaars ${ }^{1,2}$ y que ha sido la base de varios estudios en diversos países. Resultados. La técnica de Análisis de contenido obtuvo un adecuado nivel de concordancia (86\%) con el Método de interjueces. Conclusiones. Los resultados informan que existen más semejanzas que diferencias psicológicas entre ambas muestras. El presente es el primer estudio que utiliza notas suicidas entre ambos países.

Palabras clave: suicidio/psicología; análisis temático; estudio comparativo; México, Estados Unidos
Suicide is a worldwide problem and cross-cultural studies are essential in developing our understanding of suicidal behavior., ${ }^{3,4}$ The studies to date confirm that suicide rates are different among nations; suicide levels have been found to be lower in less developed countries, particularly African, Asian and Latin Ameri- can countries.,6 The study of the role of culture on suicide rates has developed from Durkheim's seminal work ${ }^{7}$ relating suicide to social integration.

Much of the research on suicidal behavior in Latin American countries has been simple descriptive samples of completed and attempted suicides. Yet, there is a

(I) Universidad de Guanajuato. León Guanajuato, México.

(2) Investigadores independientes.

(3) University of Alberta. Edmonton, Canada. 
strong possibility that these findings may be misleading because suicide rates in these countries, as in many others, are underreported. However, even when Mexico has a relatively low rate of suicide, according to a study conducted by the $\mathrm{WHO}^{8}$ amongst countries with populations over 100 million inhabitants, it turned out to be the country with the highest increase within certain age groups, under the Changes in Age-standardised Suicide Rate indicator (+61.9\% for the period 81-83/93-95), followed by countries such as India ( $+54 \%, 80-95$ period), Brazil (+13.2\% 79-81/93-95 period) and Russia $(+5.3 \%$ 80-82/96-98 period).

At the same time, several domestic studies have confirmed the rise in suicide in Mexico., ${ }^{910}$ Since 1997, suicide has become the fourth cause of death amongst people from 15 to 29 years of age. In 2000 it was the third cause of death amongst women from 15 to 19 years of age and in 2005 it was the second for the 10-19 age group. Ever since 2001, suicide has been the ninth cause of death within the working age group (15 to 64 years of age), increasing its toll on a yearly basis: from a 5.17 rate in 2001, to a 5.5 one in 2005. ${ }^{11}$

Most of the studies related to suicide in Mexico focus on socio-demographical account, such as on suicides, suicidal ideation and attempts. ${ }^{12}$ Studies on the psychological dynamics of the suicidal individual are scarce. There is only one study on suicide notes. ${ }^{13}$ Furthermore, there are only two cross-cultural studies with Mexico on suicide. Hijar, Chu \& Kraus ${ }^{14}$ presented an epidemiological study between two cities: Mexico and Los Angeles. They found that in Los Angeles suicide was more prevalent in all age groups, except in the elderly, where there were similar rates. This sparsity warrants greater cross-cultural study, especially between Mexico and the USA, given their geographical similarity, but also great cultural differences (e.g., language, religion, education). The other study was conducted by Nock et al $(2008)^{15}$ and the aim was to report the prevalence and risk factors for suicidal behaviors across 17 countries.

Understanding the act of suicide and motives behind suicide behaviour seems extremely important worldwide, ${ }^{4}$ and in order to do so, many researchers from around the world have used different methods to study suicide. Shneidman and Farberow, ${ }^{16}$ Maris,${ }^{17}$ and others have suggested the following avenues: national mortality statistics, retrospective psychological investigations (often called psychological autopsies), the study of nonfatal suicide attempts and the analysis of documents (such as suicide notes). All of them have their limitations and there are problems in obtaining them in many countries, including Mexico. Yet, each of these methods has been shown to develop our understanding of suicide and suicidal behaviour. Furthermore, from a cross-cultural perspective, one has to be careful selecting the methods of study, because of the risk of validity and reliability problems between different cultures. ${ }^{18}$ Our method will be the study of suicide notes.

Early research ${ }^{19,20}$ on suicide notes largely used an approach that incorporated descriptive information. Subsequent methods, using Frederick' ${ }^{21}$ scheme for methods of analysis have used content analysis, classification analysis and theoretical-conceptual analysis. Each of these approaches has had utility, although Frederick suggested that simple content analysis has limitations (such as noting that the word "love" occurs frequently). Classification schemes use data such as age, sex, marital status, educational level, employment status and mental disorder. ${ }^{21} \mathrm{Ho}$ and his colleagues ${ }^{22}$ developed the most widely used classification scheme; they studied suicides notes in Hong Kong. A similar classification scheme has been used in India, ${ }^{23} \mathrm{Mexico}^{13}$ and Turkey. ${ }^{24}$ However, there are limitations; the data are not entirely consistent and differences in collection occur. Yet, the studies have also supported the value of the data, the notion that suicide is complex and the validity of generalizing from suicide note writers to all suicides, ${ }^{22,25,15}$ warranting, among other things, more in-depth study of suicide notes in different cultures.

Only a very few studies have utilized a theoreticalconceptual analysis, ${ }^{26}$ despite the assertion in the first formal study of suicide notes ${ }^{21}$ that such an approach offers much promise. To address this lack, over 30 years ago, Leenaars ${ }^{25-28}$ et al. Has applied a logical, empirical analysis to suicide notes. The method permits a theoretical analysis of suicide notes, augments the effectiveness of controls, and allows us to develop some theoretical insight into the vexing problem of suicide that may have cross-cultural application.

The method has been previously described in detail. ${ }^{25,2,26}$ It treats suicide notes as an archival source. This source is subjected to the scrutiny of control hypotheses, following an ex post facto research design. This would call for suicide protocol, such as notes to be recast in different theoretical contexts (hypotheses, theories, models) for which lines of evidence of each of these positions can then be pursued in the data. Carnap's logical and empirical procedures ${ }^{29}$ can be utilized for such investigations. To date, the theories of 10 suicidologists, as noted earlier, have been investigated: A. Adler, L. Binswanger, S. Freud, C. G. Jung, K. A. Menninger, G. Kelly, H. A. Murray, E. S. Shneidman, H. S. Sullivan and G. Zilboorg. In order to test the formulations, Carnap's positivistic procedure ${ }^{29}$ calls for the translating of theoretical formulations into observable (specific) protocol sentences. ${ }^{30}$

To summarize from a series of empirical studies (e.g., age, sex, method used, nation) of the theories of 
the 10 suicidologists, a number of theoretical propositions/implications (or protocol sentences) have been identified to be observable in various samples of notes. In his model, Leenaars isolated 100 protocol sentences from each of the 10 theorists and reduced them to 35 sentences; 23 protocol sentences were found to be highly predictive (described) for the content of suicide notes (i.e., one standard deviation above the mean of observations) and 17 protocol sentences significantly discriminated genuine suicide notes from simulated notes (i.e., control data) (with five sentences being both). ${ }^{25,27,1}$ One unique finding of these studies is that there are considerable age differences in the suicide notes, but not sex. ${ }^{2,28}$ After a series of studies utilizing this model, using Cluster Analysis, the protocols were reduced to eight clusters, grouped in five intrapsychic and three interpersonal aspects: 1) unbearable pain, 2) cognitive constriction, 3 ) indirect expressions, 4) inability to adjust (psychopathology), 5) ego (vulnerability), 6) interpersonal relationships, 7) rejection-aggression, and 8) identification-egression. ${ }^{1,2,28}$ Leenaars $^{24,1}$ proposed a meta-frame to organize the clusters into intrapsychic and interpersonal elements. Suicide can be, in fact, seen as an intrapsychic drama on an interpersonal stage. Suicide can be theoretically understood, thus, from the proposed theory (templates, constructs, and frames), that is only one point of view, but the elements have utility in understanding suicide, not only in the USA or Mexico, but elsewhere. These common dimensions (or sameness) are what suicide is. Not necessarily the universal, but certainly the most frequent or common characteristics provide us with a meaningful conceptualization of suicide. The theory presented is an attempt to outline an empirically supported one. There are few such theories in suicidology and, indeed, one that has cross-cultural applicability.

Independent research on suicide notes, ${ }^{31}$ investigation of suicidal internet writing, ${ }^{32}$ and biographical studies of suicides ${ }^{33}$ have supported the utility of the approach to note or any narrative analysis. In-depth studies of inter-judge reliability ${ }^{31}$ show that the percentage of inter-judge agreement has been satisfactory $(>85 \%){ }^{34}$

\section{Cross-cultural studies}

International studies are not only rare in the study of suicide notes, but suicide in general, not only in Mexico. ${ }^{4}$ Much of our understanding of suicide may, however, be culture-specific. We simply do not know whether an analysis of suicide notes in the United States is applicable to say, Mexico and vice versa. Shneidman ${ }^{35}$ noted that when making "cross-cultural comparisons do not make the error of assuming that a suicide is a suicide".
Studies of suicide in different cultures and nations show differences, despite also similarities, ${ }^{36}$ for example, a study by Gonzalez-Forteza et al, ${ }^{37,38}$ in Mexico. Suicide has different meanings for different people. There are only a few studies, for example, on suicide notes from different countries. Leenaars ${ }^{39}$ examined 56 suicide notes from Canada and the United States, whose writers were matched for age and sex (this was the first cross-cultural study of suicide notes). None of the intrapsychic or interpersonal aspects differed. Subsequently, studies from Germany, ${ }^{40}$ the United Kingdom, ${ }^{41}$ Hungary, ${ }^{42}$ Russia $^{43}$ and Australia ${ }^{44}$ supported this observation. Primarily, differences observed were within the interpersonal realm, i.e., the stage but not consistently. For example, the Russian notes reported more interpersonal elements of aggression, murderous impulses, revenge and wanting escape. ${ }^{36}$

Suicide notes, and by implication, the psychological dimensions of suicide, may be similar in Canada, Germany, Hungary, the USA and so on. These studies, however, have been conducted among non-Latin nations. We believe that cultural and religious differences may well have an important effect on suicide acts. For example, Latin-American communities have significantly lower rates of suicide than populations in Europe, Australia, and other North American countries. ${ }^{5}$

There have been no published comparisons between the suicide notes in Mexico and the United States. These countries have very different suicide rates and markedly different cultures. It was hypothesized, consistent with previous cross-cultural studies that there would be more interpersonal differences than intrapsychic ones in the US and Mexico notes. It is assumed that culture affects these aspects more, not only because of research on suicide notes, ${ }^{36}$ but also the larger ecological model of understanding suicide, violence and health. ${ }^{45}$ This ecological model suggests that there are different levels; i.e., individual, relationship, community, and societal, that influence behaviour. The interpersonal stage in Leenaars' model is most consistent with the levels beyond the individual, and thus, includes the perception of cultural aspects.

\section{Material and Methods}

This study was conducted in the state of Guanajuato, Mexico. The official death records in this state are kept by the Bureau of Justice of Guanajuato State. All records of cause of death and facts surrounding that death are kept. For this study, files from 1995 to 2001 of 747 deaths, registered as suicide cases, 733 files were examined (14 files were missing due to administrative difficulties). Among them, 106 people who died by 
suicide $(14.46 \%)$ left one or more suicide notes, resulting in 216 notes. ${ }^{13}$

To be more specific on the sample, the Mexico notes were matched to an adult $(n=51)$ American sample; this USA sample ${ }^{25}$ has been the basis for all previous cross-cultural comparisons to date. The notes were obtained from suicide files of Los Angeles, Cal. The USA sample consisted of equal numbers $(n=20)$ in young adults (18-25), middle adults (25-55), and mature adults $(>55)$ adult groups. The notes from Mexico were reduced from 106 to 51 , largely to allow for the matching (age \pm 3 years). The reason that the complete sample could not be used is that the notes from Mexico were largely from the young and middle-age age groups, people above 55 were infrequent. The USA notes were equally matched for sex; there were only two females in the Mexican sample older than 55 years. To include the whole sample would have resulted in a skewed age sample. Leenaars ${ }^{24}$ consistently has controlled for age in the culture studies; teen notes are not included. The mean age of the Mexican notes was 36.8; the age range was 18-74. The mean age of the American notes was 37.1 ; the age range was 18-77.

Note analysis was done in two steps. The first step, included the training of the clinical judges, both Clinical Psychologist Ph.D. and psychotherapeutic practice. They studied and discussed the meanings of 35 protocol sentences in Leenaars' method, based on the literature of Leenaars' work. ${ }^{1,2,25}$ Then, they made and analysis of different notes until reaching an inter-judge reliability above $80 \%$ (.86 coefficient of concordance). ${ }^{25}$ Then, a second step was undertaken; all of the notes in this study (both Mexican and American notes) were analysed independently by two judges. These judges were both blind to socio-demographic features of the note writers, such as age and sex. The notes were analyzed for the presence of the 35 protocol sentences.

The Coefficient of Concordance ${ }^{46}$ of $90.0 \%$ for the Mexican notes and $91.51 \%$ for the American notes indicated substantial inter-judge reliability. Subsequently a reconciled rating was obtained. In order to determine whether suicide notes from the two nations differed significantly in the presence of eight sub-clusters and 35 protocol sentences, chi-squares were performed, using SPSS for Windows.*

\footnotetext{
* SPSS. SPSS for Windows (Version 14.0) [Computer software]. New Jersey: Prentice Hall, 2006
}

\section{Results}

Similar to previous studies from different countries, there was substantial evidence for the presence of the protocol sentences and clusters in both samples of suicide notes. Thus, one can conclude that the model is applicable to suicide notes of Mexico. Yet, there were a few differences with the American notes. Table I shows a comparison of contents of suicide notes from both countries according to Leenaars' suicide model. It is interesting to note the most and least frequent protocol sentences for both samples are the same. The least frequent is No. 9: "There is a poverty of thought, exhibited by focusing only on permutations and combinations of grief and grief-provoking topics"; this theme was found in only two $(3.92 \%)$ of Mexican suicide notes, while one note $(1.96 \%)$ of the American notes contained this theme. The most frequently found sentences for both nations were No. 12 "Unconscious dynamics can be concluded. There are likely more reasons to the suicide than the person is consciously aware" and No. 35: "S wants to egress (i.e., to escape, to depart, to flee, to be gone), to relieve the unbearable psychological pain." Item 12 was found in 30 (58.82\%) of the Mexican notes and in $32(62.74 \%)$ of the American notes; item 35 was found in 28 (54.90\%) of the Mexican notes, and in 34 $(66.66 \%)$ of the American notes.

When two main meta-frames (intrapsychic and interpersonal) are considered, two samples did not show any significant differences (Figure 1). This was also true for all sub-clusters; there were no significant differences between American and Mexican suicide notes with regard to themes of unbearable psychological pain, cognitive constriction, indirect expressions, inability to adjust, ego, interpersonal relations, rejection-aggression, identification-egression in general.

When one examines the specific protocol sentences in the clusters, notes from Mexico less often expressed statements of suicide as a solution to urgent problem inwards (No. 4) $\left(\chi^{2}(d f=1, N=102)=5.420, p<.05\right)$, and the unwillingness to accept the problem, choosing to escape (No. 34) $\left(\chi^{2}(d f=1, N=102)=6.746, p<.01\right)$. No other significant differences emerged.

\section{Discussion}

The findings provide further support for the multidimensional model proposed by Leenaars. ${ }^{1,2}$ Once again, there is considerable evidence of both intrapsychic and interpersonal psychological correlates of suicide. Similar to previous cross-cultural studies, there seem to be more commonalities among suicides notes from 
Table I

Frequency of endorsement of PROtocol Sentences, PeRCentages, AND Significance in MeXico (N=5 I) and USA ( $\mathrm{N}=5 \mathrm{I}$ ) notes. (Survey made in Mexico/Canada, 2008)

Cluster/Protocol sentence

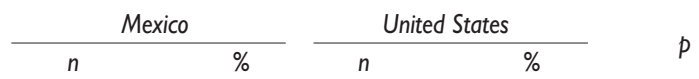

Intrapsychic

I. Unbearable psychological pain

Suicide as a relief

Suicide as a flight from trauma

$\begin{array}{lll}37 & 72.5 & 37\end{array}$

Emotional states in suicidal trauma

Loss of interest to endure

Inability to meet life's challenges

State of heightened disturbance

II. Cognitive constriction

A history of trauma

Overpowering emotions

Focus only on grief topics

\begin{tabular}{rrrrr}
30 & 58.8 & 30 & 58.8 & 1.000 \\
\hline 15 & 29.4 & 13 & 25.5 & 0.657 \\
\hline 29 & 25.0 & 21 & 41.2 & 0.113 \\
\hline 11 & 21.6 & 22 & 43.1 & $0.020 *$ \\
\hline 11 & 21.6 & 16 & 31.4 & 0.262 \\
16 & 31.4 & 11 & 21.6 & 0.262 \\
\hline 15 & 29.4 & 15 & 29.4 & 1.000 \\
\hline 9 & 17.6 & 9 & 17.6 & 1.000 \\
\hline 8 & 15.7 & 5 & 9.8 & 0.373 \\
\hline 2 & 3.9 & 1 & 2.0 & 0.558 \\
\hline 35 & 68.6 & 33 & 64.7 & 0.874 \\
\hline 10 & 19.6 & 6 & 11.8 & 0.276 \\
\hline 11 & 21.6 & 13 & 25.5 & 0.641 \\
\hline 30 & 58.8 & 32 & 62.7 & 0.685 \\
\hline 18 & 36.0 & 20 & 40.0 & 0.738 \\
\hline 11 & 21.6 & 14 & 27.5 & 0.490 \\
\hline 2 & 4.0 & 5 & 9.8 & 0.251 \\
\hline 7 & 13.7 & 6 & 12.0 & 0.796 \\
\hline 16 & 31.4 & 9 & 17.6 & 0.079 \\
\hline 12 & 23.5 & 5 & 9.8 & 0.063 \\
\hline 5 & 9.8 & 7 & 13.7 & 0.539 \\
\hline 3 & 7.8 & 4 & 7.8 & 0.695
\end{tabular}

Interpersonal

VI. Interpersonal (IP) relations

Problems determined by IP situations

Weakened by unresolved IP problems

Frustrated needs in IP realm

Frustration to a traumatic degree

Positive development not forthcoming

Regressive, intimate, relationships

\begin{tabular}{rrrrr}
29 & 56.9 & 22 & 44.0 & 0.251 \\
19 & 37.3 & 14 & 28.0 & 0.321 \\
10 & 19.6 & 13 & 25.5 & 0.477 \\
14 & 27.5 & 12 & 23.5 & 0.650 \\
17 & 33.3 & 15 & 29.4 & 0.670 \\
\hline 4 & 7.8 & 5 & 9.8 & 0.727 \\
\hline 8 & 15.7 & 5 & 9.8 & 0.373 \\
\hline 25 & 50.0 & 16 & 31.37 & 0.083 \\
\hline 10 & 19.6 & 11 & 21.6 & 0.807 \\
\hline 5 & 9.8 & 9 & 17.6 & 0.250 \\
16 & 31.4 & 12 & 23.5 & 0.375 \\
\hline 8 & 15.7 & 6 & 11.8 & 0.565 \\
\hline 4 & 7.8 & 2 & 3.9 & 0.400 \\
\hline 3 & 6.0 & 2 & 3.9 & 0.630 \\
\hline 7 & 13.7 & 3 & 5.9 & 0.183 \\
\hline 6 & 11.8 & 4 & 7.8 & 0.505 \\
\hline 37 & 60.8 & 35 & 68.6 & 0.210 \\
\hline 7 & 13.7 & 4 & 7.8 & 0.338 \\
\hline 4 & 7.8 & 14 & 27.5 & $0.009 *$ \\
\hline 28 & 54.9 & 34 & 66.7 & 0.224 \\
\hline & & & &
\end{tabular}

$* p<0.05$

VII. Rejection-Aggression

Report of a traumatic event

Narcissistic injury

Preoccupation with person

Ambivalent feelings towards a person

Aggression as self-directed

Murderous impulses

Calculation of negative effect

Revenge towards someone else

VIII. Identification-Egression

Identification with person/ideal

Unwillingness to accept life

Suicide as escape

ming




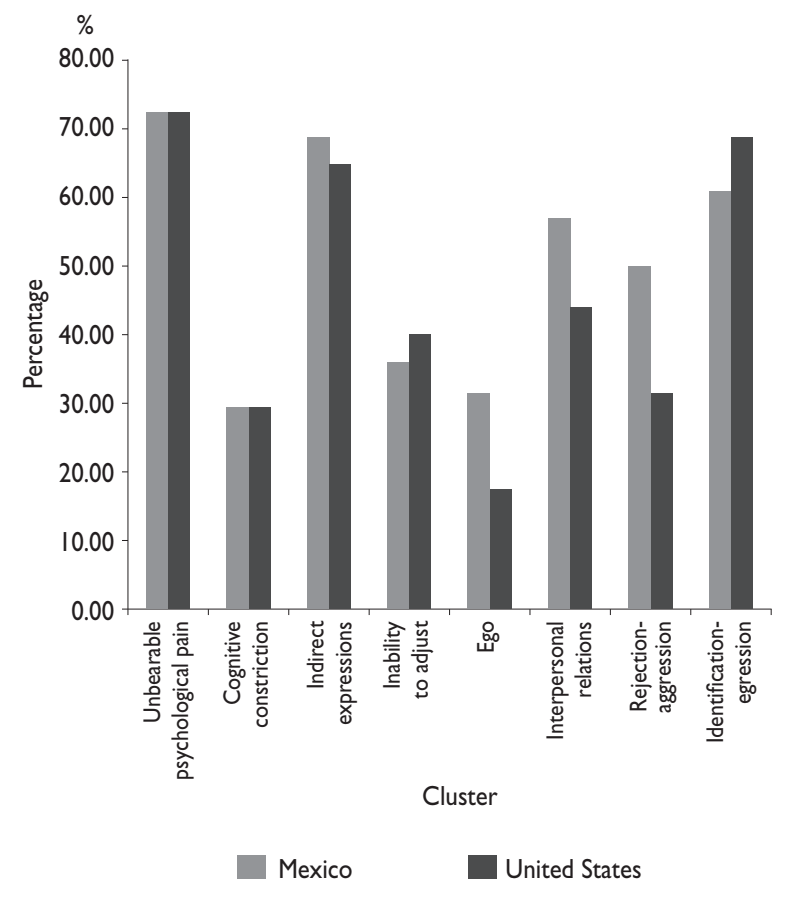

Figure I. Distribution of Cluster themes eVident in the SUICIDE NOTES. (SuRVeY MADE IN MEXICO/Canada, 2008)

Mexico and the United States than differences, despite the great cultural differences. By virtue of our human quality, people have a number of important psychological characteristics in common. No matter the country, mental constriction is mental constriction, psychopathology is psychopathology. So, the suicidal mind is the suicidal mind, whether in Mexico or the United States; research to date suggests that is equally true in Australia, ${ }^{44}$ Canada, ${ }^{39}$ Germany, ${ }^{40}$ Hungary, ${ }^{42}$ Russia, ${ }^{43}$ and the United Kingdom. ${ }^{41}$ Thus, given that Mexico is a country with collectivistic properties, and very different from the individualistic countries studied to date, the results are remarkable.

Although Mexico is a country with low rates of suicide, its steady increase over the last years is most concerning. Traditional social bonding (integration) factors such as certainty of employment, and quality of religious diversity, have weakened. Urbanization processes have decreased rural life, have led to huge migration waves in many states and have given way to the disappearance of traditional forms of family. Globalization has permeated previously existent psycho-social problems in developed countries, and also in Mexico. ${ }^{4}$ Solidarity nets based on kinship and religious attachment have been dramatically modified during the last decade, leaving behind major social changes; an example of this, we believe, is the increase in suicide rates. This increase in Mexico clashes against the scarcity of prevention and care programmes for suicidal behaviour. This contrasts with USA programmes that have been implemented for decades now.

As we can see from the results, the content of suicide notes in Mexico do not differ from those found in the USA; thus, we can infer that the psychological suffering of individuals who experience certain personal and familial or interpersonal vulnerability in both countries show similar characteristics. It is of note that suicidal people in Mexico, compared to Americans, do not write about suicide as an escape. A similar significant observation had previously been made about escape in American notes, in comparison to Canadian and Australian notes. Maybe, compared to people in other countries, Mexicans rarely see suicide as an escape, warranting greater study. There is, further, the complex problem of accepting the null hypothesis in science. Furthermore, since this conclusion is based on one study, the conclusions warrant much greater study, especially given the large migration of people from Mexico to the USA and people taking with them their ways of life, including suicide.

\section{References}

I. Leenaars A. Suicide.A multidimensional malaise. Suicide Life Threat Behav 1996;26:221-235.

2. Leenaars A. Psychotherapy with suicidal people. Chichester:John Wiley \& Sons, 2004.

3. Leenaars A, Connolly J, Cantor C, EchoHawk M, Gailiene D, He Z, et al. Suicide, assisted suicide, and euthanasia: International perspectives. Ir J Psychol Med 200I;18:33-37.

4. World Health Organization (WHO). World report on violence and health. Krug EG et al., eds. Geneva: WHO, 2002.

5. Eshun S. Sociocultural determinants of suicide ideation:A comparison between American and Ghanian college samples. Suicide Life Threat Behav 2003;33: I65-I7I.

6. Lester D. Suicide in an international perspective. Suicide Life Threat Behav 1999;24:245-255.

7. Durkheim E. Suicide:A study in sociology. (J.A. Spaulding \& G. Simpson, Trans.). Glencoe, IL: Free Press, I95I (Original work published 1897). 8. World Health Organization (WHO). The World Health Report 2000. [internet series] Mental health: new understanding, new hope 200 I [consulted 2002 may 20]. Avalaible in: http://www.who.int/whr.200I. 9. Aguilar J, Coutino R, Gonzalez-Leon M, Lopez M. A glance to suicide in Chiapas. Psiquis 1997; 6(5): 95- 102.

10. Gonzalez-Forteza C, Marino M, Mondragon L, Medina-Mora ME. Suicide attempts in students from Pachuca, $\mathrm{Hgo}$, and its relationship with depressive mood and substance abuse. Revista Mexicana de Psicologia 1998; I5(2): I65-175. 
II. Department of Health Mexico. Mortality Causes. [online monograph] 2005 [consulted 2007 December 20]. Available in: http://sinais.salud.gob. $\mathrm{mx} / \mathrm{mortalidad} / \mathrm{tabs} / \mathrm{m} \_005 . x \mathrm{~s}$

12. Jimenez-Tapia A, Gonzalez-Forteza C. Twenty-five years of research on suicide at the Epidemiological and Psychosocial Research Department of the National Institute of Psychiatry, Ramón de la Fuente. Salud Mental 2003; 26(6):35-46.

13. Chavez-Hernandez A, Paramo-Castillo D, Leenaars A, Leenaars L. Suicide notes in Mexico:What do they tell us? Suicide Life Threat Behav 2006;36:709-715.

14. Hijar M, Chu L, Kraus JF. Cross-national comparison of injury mortality: Los Angeles country, California and Mexico City, Mexico. Int J Epidemiol 2000;29:7I5-72I.

15. Nock M, Borges G, Bromet E,Alonso J,Angermeyer M, Beautrais A, et al. Cross-national prevalence and risk factors for suicidal ideation, plans and attempts. Br J Psychiatry 2008; 192:98-105.

16. Shneidman E, Farberow N. (Eds.). Clues to suicide. New York: Harper \& Row, 1957.

17. Maris R. Pathways to suicide. Baltimore, MD: John Hopkins University Press, 1981.

18. Hjelmeland H, Kinyanda E, Knizek BL, Qwens V, Nordvik H, Svarva $K$. A discussion of the value of cross-cultural studies in search of the meaning(s) of suicidal behavior and the methodological challenges of such studies. Arch Suicide Res 2006;10:15-27.

19. Boismont B. Du suicide et la folie suicide. Paris: Germer Bailliere, 1856

20. Wolff H. Suicide notes. American Mercury 1931;24:264-272.

21 . Frederick C. Suicide notes:A survey and evaluation. Bulletin of Suicidology, March 1969;27-32.

22. Ho T, Yip P, Chiu C, Halliday P. Suicide notes: what do they tell us? Acta Psychiatrica Scandinavica 1998;98:467-473.

23. Girdhar S, Leenaars A, Dogra TD, Leenaars L, Kumar G. Suicide notes in India: what do they tell us? Arch Suicide Res 2004;8:179-185.

24. Demirel B,Akar T, Sayin A, Candansayar S, Leenaars A. Farewell to the world: Suicide notes from Turkey. Suicide Life Threat Behav 2007;38: I23128.

25. Leenaars A. Suicide notes. New York: Human Sciences Press, 1988.

26. Leenaars A, Balance W.A logical empirical approach to the study of suicide notes. Can J Behav Sci 1984;16:248-256.

27. Leenaars A. Suicide across the adult life-span: an archival study. Crisis 1989;|10:|32-|5|.

28. Leenaars A, de Wilde E, Wenckstern S, Kral M. Suicide notes in adolescents:A life-span comparison. Can J Behav Sci 200I;33:47-57. 29. Carnap R. Psychology in physical language. In A.Ayer (Ed.), Logical positivism. New York: Free Press (Original work published 1931);1959:165-197.
30. Ayer A. Logical positivism. New York: Free Press, 1959.

31. O'Connor R, Sheeby N, O'Connor D.A thematic analysis of suicide notes. Crisis 1999; 20: 106-II4.

32. Barak A, Miran O.Writing characteristics of suicidal people on the internet:A psychological investigation of emerging social environments. Suicide Life Threat Behav 2005;35:507-524.

33. Lester D.A comparison of fifteen theories of suicide. Suicide Life Threat Behav 1994;24:80-88.

34. Shaughnessy J, Zechmeister E, Zechmeister J. Research methods in psychology. New York: McGraw-Hill, 2000.

35.Shneidman E. Definition of suicide. New York:Wiley, 1985.

36. Leenaars A. Suicide:A cross-cultural theory. In F. Leong \& M. Leach

(Eds.). Suicide among racial and ethnic groups:Theory, research, and practice. New York: Routledge, 2007:13-37

37. Gonzalez-Forteza C, Ramos L, Caballero MA, Wagner F. Psychosocial correlates for depression, ideation and suicide attempts in Mexican adolescents. Psicothema 2003; 15(4): 524-532.

38. Gonzalez-Forteza C, Chavez-Hernández AM,Alvarez M, Saldaña A, Carreño S, Pérez R. Prevalence of deliberate self-harm in adolescents students in Guanajuato State, México: Measurement: 2003.J Soc Behav Pers 2005; 33: 777-792.

39. Leenaars A. Suicide notes from Canada and United States. Perceptual and Motor Skills 1992; 74: 278.

40. Leenaars A, Lester D, Wenckstern S, Heim N. Suicide notes from Germany and the United States. Suizidprophylaxe 1994; 3: 99-101. [In German]

4I. O'Connor R, Leenaars A.A thematic comparison of suicide notes drawn from Northern Ireland and the United States. Current Psychology 2004; 22: 339-347.

42. Leenaars A, Fekete S, Wenckstern S, Osvath P. Suicide notes from Hungary and the United States. Psychiatrica Hungarica 1998; I3: I47-I59. [In Hungarian]

43. Leenaars A, Lester D, Lopatin A, Schustov D,Wenckstern S. Suicide notes from Russia and the United States. Social and General Psychiatry 2002; (I2) 3: 22-28. (In Russian).

44. Leenaars A, Haines J,Wenckstern S, Williams C, Lester D. Suicide notes from Australia and the United States. Perceptual and Motor Skills 2003;

92: I28I-I 282.

45. Dahlberg L, Krug E.Violence - a global public health problem. In World Health Organization (Ed.),World report on violence and health. Geneva: World Health Organization, 2002:3-21.

46. Siegel S. Nonparametric statistics. New York: Mcgraw-Hill, 1956. 